\title{
Adaptive Elements in Internet-Delivered Psychological Treatment Systems: Systematic Review
}

Suresh Kumar Mukhiya ${ }^{1}$, MSc; Jo Dugstad Wake ${ }^{2}$, PhD; Yavuz Inal ${ }^{3}, \mathrm{PhD}$; Ka I Pun ${ }^{1}$, PhD; Yngve Lamo ${ }^{1}$, Prof Dr

${ }^{1}$ Western Norway University of Applied Sciences, Bergen, Norway

${ }^{2}$ NORCE Norwegian Research Centre, Bergen, Norway

${ }^{3}$ University of Bergen, Bergen, Norway

\section{Corresponding Author:}

Suresh Kumar Mukhiya, MSc

Western Norway University of Applied Sciences

Inndalsveien 28

Bergen, 5063

Norway

Phone: 4755585800

Email: $\underline{\text { skmu@hvl.no }}$

\section{Abstract}

Background: Internet-delivered psychological treatments (IDPTs) are built on evidence-based psychological treatment models, such as cognitive behavioral therapy, and are adjusted for internet use. The use of internet technologies has the potential to increase access to evidence-based mental health services for a larger proportion of the population with the use of fewer resources. However, despite extensive evidence that internet interventions can be effective in the treatment of mental health disorders, user adherence to such internet intervention is suboptimal.

Objective: This review aimed to (1) inspect and identify the adaptive elements of IDPT for mental health disorders, (2) examine how system adaptation influences the efficacy of IDPT on mental health treatments, (3) identify the information architecture, adaptive dimensions, and strategies for implementing these interventions for mental illness, and (4) use the findings to create a conceptual framework that provides better user adherence and adaptiveness in IDPT for mental health issues.

Methods: The review followed the guidelines from Preferred Reporting Items for Systematic Reviews and Meta-Analyses (PRISMA). The research databases Medline (PubMed), ACM Digital Library, PsycINFO, CINAHL, and Cochrane were searched for studies dating from January 2000 to January 2020. Based on predetermined selection criteria, data from eligible studies were analyzed.

Results: A total of 3341 studies were initially identified based on the inclusion criteria. Following a review of the title, abstract, and full text, 31 studies that fulfilled the inclusion criteria were selected, most of which described attempts to tailor interventions for mental health disorders. The most common adaptive elements were feedback messages to patients from therapists and intervention content. However, how these elements contribute to the efficacy of IDPT in mental health were not reported. The most common information architecture used by studies was tunnel-based, although a number of studies did not report the choice of information architecture used. Rule-based strategies were the most common adaptive strategies used by these studies. All of the studies were broadly grouped into two adaptive dimensions based on user preferences or using performance measures, such as psychometric tests.

Conclusions: Several studies suggest that adaptive IDPT has the potential to enhance intervention outcomes and increase user adherence. There is a lack of studies reporting design elements, adaptive elements, and adaptive strategies in IDPT systems. Hence, focused research on adaptive IDPT systems and clinical trials to assess their effectiveness are needed.

(J Med Internet Res 2020;22(11):e21066) doi: 10.2196/21066

\section{KEYWORDS}

cognitive behavioural therapy; internet-delivered psychological treatment; adaptive treatment; internet-based treatment; adaptive system; mental health; literature review; architecture centric development; tailored internet interventions; flexible mHealth internet interventions 


\section{Introduction}

Research accounts for internet-delivered psychological treatment (IDPT) as a useful therapeutic tool [1] with increased potential to provide evidence-based mental health interventions for the far-reaching population at a lower cost [2,3]. However, actual user adherence to such interventions is low [4-8]. These results raise a critical question in IDPT: how can the clinical effect of IDPT be improved? Therefore, it is relevant to focus on the factors associated with enhancing user adaption toward such interventions.

Some studies have found that providing therapist contact for online guidance and support during interventions increases adherence and effect sizes [7,9-14]. Clarke et al [15] added telephone calls and postcard reminders from therapists to increase user adherence. The study concluded by discovering no significant difference between intervention groups with or without reminders. However, a similar study done by Farrer et al [16] to evaluate the effectiveness of a 6-week IDPT for depression with and without telephone interaction concluded that IDPT is effective both with and without tracking for reducing depression. The results indicated that the success of an intervention depends on the environmental settings in which they are performed [16]. Similarly, some studies increased the frequency of emails from therapists to increase user adherence. Klein et al [17] conducted a study to examine if the frequency of therapists' contact (from 1 email per week to 3 emails per week) made a difference in user adherence. The study concluded that the effectiveness of IDPT might be independent of the frequency of therapist support. Hilvert-Bruce et al [18] conducted a study to investigate if the drop out of users of IDPT was caused by lack of treatment efficacy, if changes in the choice of treatments, reminders, and financial cost improves adherence, and finally, if the addition of clinical contact improves user adherence. The results of the study showed that adding reminders, and increasing the choice of treatments, cost, timing, and contact with clinicians improved user adherence [18]. These findings illustrate that the baseline predictors of adherence vary across studies.

A systematic review by Christensen et al [7] discovered that disease diversity, treatment length, and predicted chronicity are essential factors contributing to user adherence in IDPT. Similarly, clinical severity has also been indicated as one of the crucial factors contributing to user adherence in web-based interventions targeting problematic drinking [19]. Similar factors have been identified as the most prominent factors in user adherence toward IDPT. However, only a few studies have discussed why the target group chose not to adhere to any specific IDPT system. The most common reasons cited for nonadherence in state-of-art studies were that (1) people believe they have made sufficient progress, (2) users reported there was too much content without much flexibility, (3) users reported that treatments were too complicated, (4) treatments did not match users' expectations, (5) there was a lack of therapist contact, and (6) there was a lack of personalization. A meta-analysis by Vandereycken and Devidt [20] concluded that the target groups chose not to adhere to the eating disorder treatment because they believed they had achieved sufficient progress. However, a lack of progress is not related to nonadherence, according to several other studies [7,17]. According to a survey done by Johansson et al [21], participants chose not to adhere to the treatment when they were unable to perceive a compatible correlation between the length of weekly text modules and the conditions in their personal life. Moreover, the participants found the content to be a tiresome burden because of the length of the text modules and time consumed to go through them. Furthermore, the fixed format of the content sent to the participants each week was perceived as inflexible for some participants. Content complexity was perceived as challenging to comprehend and to process by individuals participating in interventions $[8,21]$, especially when these individuals considered themselves to have attention problems or limited reading and writing skills. Participants ' knowledge and expectations about the treatment process have shown to influence user trust and hence adherence [22]. Johansson et al [21] outlined in their study that participants mentioned they were grateful for being offered the treatment. However, not all of them appeared to be fully aware of the treatment and its significance. A similar conclusion was drawn by Alaoui et al [23], who identified higher treatment credibility to be the most influential prognostic factor for user adherence. Feedback has been thought to increase user adherence for $65 \%$ of intervention participants [19]. Similarly, a study by Johansson et al [21] revealed that the lack of therapist support during interventions was perceived by patients as a sign that therapists did not care about their health care issues. Furthermore, some participants reported that they never prioritized their personal development because they were aware that face-to-face meeting was not required. A recent study on mental health indicated that compliance failure can result from a lack of personalization [24]. A study by Doherty [25] claimed to have improved user adherence with the IDPT system by focusing on user personalization.

Most of the research examining the causes of low user adherence to IDPT has discovered that the reasons associated with patients were about personal and interpersonal competencies, and lack of resources rather than the diagnosis or health problem severity [7]. Moreover, it was about the patient's intrinsic motivation to change, their self-relatedness, and their receptivity to change. Levey and Clarkin [26] characterized this reason as the patient variable. Considering this as the reason for premature termination of interventions indicates a need to investigate the reasons and circumstances for nonadherence further. Specifically, this indicates a gap in the literature concerning the in-depth exploration of the subjective reasons for nonadherence in online psychological interventions. In general, the factors affecting premature termination of participants from IDPT, as outlined by Johansson et al [21], can be characterized by the interaction between the participant's perception of the treatment (content complexity, therapist feedback, and information about significance) and the participant's situation (awareness about the treatment, availability, daily routines, treatment expectations, and perceived language skills). Analogously, a report by the World Health Organization [27] distinguished five interacting dimensions affecting adherence to medication, therapy, and health care in general: socioeconomic factors, therapy-related factors, 
patient-related factors, condition-related factors, and health system/health care team-related factors. The same report claimed that relatively limited research has been done on the effects of health system/health care team-related factors on adherence.

In this paper, we propose that in addition to these two factors (perception of treatment and personal situations), a third factor is contributing to user adherence: the adaptiveness of the IDPT system. There are two perspectives here: adaptiveness and information architecture (IA) [28]. First, IA is associated with how people cognitively process information and enhances the ability of the participants to find information. Second, adaptiveness refers to an ability in the system to change in response to environmental changes. The former perspective makes the information presented in IDPT comprehensible and discoverable, while the latter makes the IDPT more personalized. In this paper, we argue that both adaptiveness and IA are essential elements that contribute to user adherence in IDPT. Hence, we aim to investigate the following research questions in this literature review: (1) what are the most prevalent choices of IA in existing IDPT systems, and what is the primary rationale behind choosing an IA?, (2) what are the primary adaptive elements in IDPT systems, and how do these elements contribute to enhancing user adherence and intervention outcomes?, (3) what are the primary adaptive strategies used in IDPT systems, and how do these adaptive strategies consume adaptive elements to generate personalized experience for mental health patients?, and (4) how can we generalize the results to create a conceptual framework that can be used in the creation of an adaptive IDPT system for mental health interventions?

To the best of our knowledge, limited research has examined the experience of nonadherence in the IDPT system based on IA and adaptiveness as affecting factors. In this study, we focus on reviewing the adaptive elements and IA in the current IDPT systems used for the treatment of mental illness. Our review shows that several different terms are being used to describe similar IDPT systems. Interventions involving the internet as the communication mechanism are referred to as web-based treatments, web-based interventions, online treatment, computerized psychotherapy, e-therapy, eHealth, internet-based cognitive behavioral therapy, digital interventions, web app-based psychotherapy treatments, therapeutic web-based interventions, eHealth interventions [29], and others. Analogously, other variations include creation of technical platforms such as Interapy [30], Deprexis [31], ULTEMAT [32], digital behavior change interventions [33], and smartphone-based apps with specific brand names [34]. The absence of any taxonomic preferences and professional ontology makes the field of IDPT inconsistent and ambiguous. The use of a multitude of terms and labels to describe similar health interventions makes it difficult to search the results of studies. To be consistent, we chose to use the term IDPT, as suggested by Andersson et al [35].

\section{Methods}

We conducted the review according to the PRISMA (Preferred Reporting Items for Systematic Reviews and Meta-Analyses) guidelines [36]. Here, we present the methodology we used to search, analyze, and extract pertinent information from relevant studies.

\section{Search Strategy}

We searched the databases recommended by Cochrane [37], including Medline (PubMed), ACM Digital library, PsycINFO, EMBASE, CINAHL, and Cochrane, to identify studies. In addition, we hand-searched the reference list of the selected publications to retrieve additional relevant publications. The search string included Adaptive, OR Flexible, OR Tailored, AND Internet, AND Interventions, AND Mental Health (see Multimedia Appendix 1 for detailed search string). Each term included medical subject headings, and the search was done on full-text papers. The search was limited to all papers published in English from January 2000 to January 2020. The database searches and subsequent review were performed by the same two authors (SKM and JDW) independently in a double-blind process.

\section{Eligibility Criteria}

We included studies in which the articles met the following inclusion criteria: (1) discussed an intervention delivered through the internet (web- or mobile-based), (2) attempted to provide adaptive (dynamic, tailored, flexible) interventions by using adaptive strategies, (3) targeted a mental health disorder defined by the Diagnostic and Statistical Manual of Mental Disorders, Fifth Edition (DSM-5) [38], and (4) was published between January 2000 and January 2020. No data restrictions were imposed. The following exclusion criteria were used: (1) not written in the English language, (2) not a full-text paper or published in the form of a short paper, extended abstract, abstract or poster, (3) designed as nonempirical findings such as opinion papers, reviews, editorials, letters, agendas, or study protocols, (4) dealt with adaptive technology in any domain other than mental health, or (5) was not about adaptive technology.

\section{Review Procedure}

The selection of studies took place in three phases based on the review of the title, keywords, abstract, and full text. Title and abstract screening were carried out blinded for author, journal, and date of publication. Any doubtful papers were included in the next phase, and disagreement was resolved through discussion. After identifying 3341 relevant papers in the initial database search, 372 duplicate papers were removed, and 2969 unique papers remained. In the screening step, the resulting list of 2969 papers was reviewed independently by the same two authors according to inclusion and exclusion criteria. By reviewing the title, abstract, and keywords, 105 eligible papers were retrieved. Two main reasons for the substantial exclusions were (1) the search engine returned the results containing any of the search terms, although they were logically connected, and (2) most of the papers were related to mental health without any reference to IDPT. Full texts were evaluated to determine 
the eligibility of the remaining papers. The full texts of the 105 eligible papers were assessed independently by the same authors. Any discrepancies between the authors regarding the selection of the papers were resolved through discussion. In total, 74 papers were excluded in this round, and the selection process led to the inclusion of 31 papers, as illustrated in Figure 1. The most common reason for exclusion in this phase was that the publication did not discuss an intervention delivered via the internet. Other publications were excluded because they focused on other types of health care interventions without clear information about IA, user adherence, or adaptive strategies.

Figure 1. Preferred Reporting Items for Systematic Reviews and Meta-Analyses (PRISMA) flow diagram for this systematic review.
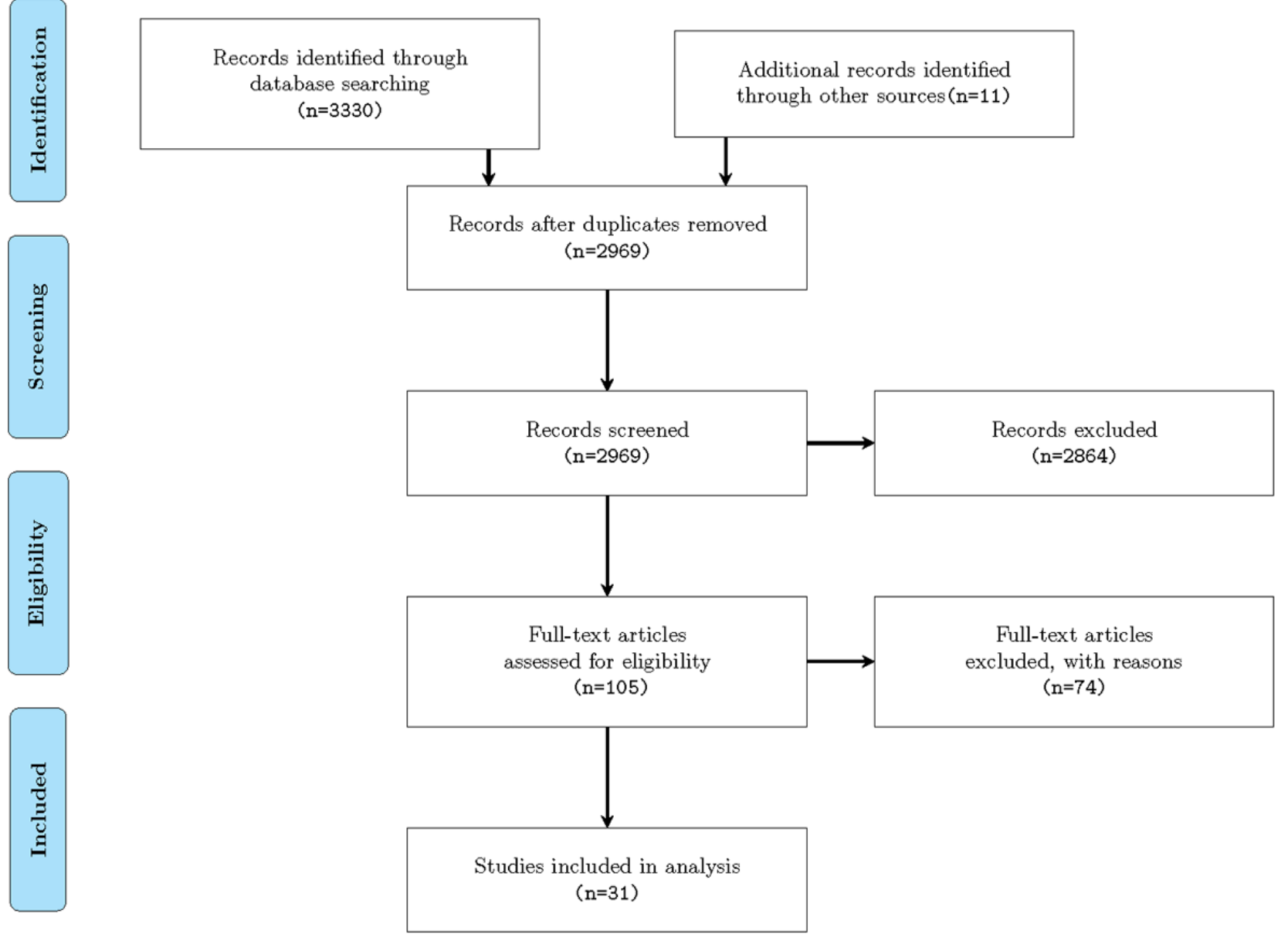

\section{Data Extraction and Synthesis}

Data from the included studies were extracted, verified, and tabulated for review by the authors. From the selected studies, we chose to obtain the main adaptive elements, adaptive strategies used, adaptive dimension, and actor involved in adaptation. Multimedia Appendix 2 provides a detailed summary of the analysis of the 31 articles in the review. All of the articles in the analysis are listed in the references [11-14,24,32,39-63]. We evaluated all of the relevant studies based on the adaptive IDPT model previously described [28]. As mentioned in the study [28], we extracted the core components of the adaptive reference model, including adaptive elements, adaptive dimensions, IA, and adaptive strategies. The rest of our results are based on these core components.

\section{Data and Software Availability}

For purposes of transparency and reproducibility of our study, we have published the resulting data, code, and procedures on
GitHub [64]. The GitHub repository includes raw articles extracted from database searches, keyword formulation documents, preprocessed article lists, and a literate programming script used for data preprocessing, analysis, and visualization.

\section{Results}

\section{Mental Health Illnesses Addressed}

A significant number of the included studies addressed depression $(n=11)$ and anxiety disorder $(n=7)$, followed by general mental health issues $(n=8)$, such as well-being, mindfulness, and goal achievement. Furthermore, some studies reported the use of adaptiveness in other areas such as insomnia $(n=2)$, social psychology $(n=1)$, attention deficit hyperactivity disorder $(n=2)$, posttraumatic stress disorder $(n=2)$, suicidality $(n=2)$, and substance misuse $(n=1)$. The full list of types of mental health problems addressed in the relevant studies is presented in Table 1. 
Table 1. Types of mental illness for which an adaptive system was built.

\begin{tabular}{|c|c|}
\hline Mental illnesses & Study references \\
\hline \multirow[t]{11}{*}{ Depression } & Tsiakas et al, 2015 [40] \\
\hline & Levin et al, 2018 [41] \\
\hline & Burns et al, 2011 [50] \\
\hline & Rebar et al, 2016 [51] \\
\hline & Malins et al, 2020 [54] \\
\hline & Van Gemert-Pijnen et al, 2014 [56] \\
\hline & Lillevoll et al, 2014 [24] \\
\hline & Achtyes et al, 2015 [57] \\
\hline & Wallert et al, 2018 [58] \\
\hline & Kop et al, 2014 [61] \\
\hline & D’Alfonso et al, 2017 [63] \\
\hline \multirow[t]{7}{*}{ Anxiety disorder } & Tsiakas et al, 2015 [40] \\
\hline & Levin et al, 2018 [41] \\
\hline & Walter et al, 2007 [45] \\
\hline & Batterham et al, 2017 [48] \\
\hline & Malins et al, 2020 [54] \\
\hline & Achtyes et al, 2015 [57] \\
\hline & Wallert et al, 2018 [58] \\
\hline \multirow[t]{2}{*}{ Insomnia } & Forsell et al, 2019 [59] \\
\hline & Erten-Uyumaz et al, 2019 [60] \\
\hline Substance use & Batterham et al, 2017 [48] \\
\hline \multirow[t]{2}{*}{ Suicidality } & Delgado-Gomez et al, 2016 [42] \\
\hline & Batterham et al, 2017 [48] \\
\hline Social psychology & Rachuri et al, 2010 [62] \\
\hline Bipolar disorder & Dodd et al, 2017 [14] \\
\hline Stress & Konrad et al, 2015 [47] \\
\hline \multirow[t]{2}{*}{ Posttraumatic stress disorder } & Tielman et al, 2019 [43] \\
\hline & Eisen et al, 2016 [46] \\
\hline Smoking cessation & Lagoa et al, 2014 [44] \\
\hline Attention deficit hyperactivity disorder & Nahum-Shani et al, 2012 [12] \\
\hline \multirow[t]{8}{*}{ General mental health } & Iorfino et al, 2019 [39] \\
\hline & Bannink et al, 2012 [11] \\
\hline & Berrouiguet et al, 2018 [49] \\
\hline & Ketelaar et al, 2014 [52] \\
\hline & Coyle et al, 2010 [53] \\
\hline & Kitagawa et al, 2020 [13] \\
\hline & van Os et al, 2017 [55] \\
\hline & van de Ven et al, 2017 [32] \\
\hline
\end{tabular}

\section{Intervention Platform}

Based on our findings, the communication media used to administer internet-facilitated interventions to patients can be classified into three categories: web apps, mobile apps, and computer games. A significant number of the included studies were based on web apps $[11,14,24,39,43,49,50,52,54,56,63]$, followed by mobile apps $[13,32,41,49,50,55,60,61]$ and a game-based intervention [53]. There was only one paper that applied both web and mobile technologies for internet-based 
intervention. However, a lot of studies did not report the mode of delivery.

\section{IA}

IA is concerned with the art and science of organizing and labelling components of web apps, intranets, software, and online communities to enhance their usability and accessibility. IA plays a vital role in web app development, and a good architecture can improve the ability of employees and customers to find information and decrease the app's maintenance cost

Table 2. Types of information architecture used in the reviewed studies.

Information architectures
Tunnel-based IA

\section{Study references}

Iorfino et al, 2019 [39]

Konrad et al, 2015 [47]

Batterham et al, 2017 [48]

Kitagawa et al, 2020 [13]

Hybrid IA

D'Alfonso et al, 2017 [63]

Matrix IA

Levin et al, 2018 [41]

Lagoa et al, 2014 [44]

Van Gemert-Pijnen et al, 2014 [56]

Hierarchical IA

Tielman et al, 2019 [43]

Bannink et al, 2012 [11]

Berrouiguet et al, 2018 [49]

Not clear/not reported
Coyle et al, 2010 [53]

Tsiakas et al, 2015 [40]

Delgado-Gomez et al, 2016 [42]

Walter et al, 2007 [45]

Bannink et al, 2012 [11]

Burns et al, 2011 [50]

Rebar et al, 2016 [51]

Ketelaar et al, 2014 [52]

Malins et al, 2020 [54]

Kitagawa et al, 2020 [13]

van Os et al, 2017 [55]

Lillevoll et al, 2014 [24]

Dodd et al, 2017 [14]

Achtyes et al, 2015 [57]

Wallert et al, 2018 [58]

Forsell et al, 2019 [59]

Erten-Uyumaz et al, 2019 [60]

Kop et al, 2014 [61]

van de Ven et al, 2017 [32]

Rachuri et al, 2010 [62]
The analysis of Table 2 answers our first research question. Most of these IAs fall into four categories: (1) tunnel-based design, (2) matrix design, (3) hierarchical design, and (4) hybrid design. A previous study [65] showed that $90 \%$ of the available IDPT systems used a tunnel-based design, where users navigate sequentially to search for information. A tunnel-based design 
is analogous to watching TV series, reading textbooks, attending academic classes, or attending multiple clinical sessions. An argument for tunnel-based design is that the experience is less likely to overwhelm users with information and options [66]. The tunnel-based design is probably also the default IA design alternative in many projects and is the easiest to implement.

\section{Adaptive Elements}

Adaptive elements are the main components that are personalized for the user. As reported in a previous study [28], the main adaptive elements can be intervention content, design, assessment tests, IA, content presentation, content complexity, content recommendation, user interface (such as navigation system, search engines), feedback, notifications/reminders/alerts, behavioral activities, exercises, and reporting/dashboards. We report the full list of adaptive elements found in the relevant studies in Table 3.

Numerous studies $(9 / 31,29 \%)$ reported adapting the content of the intervention. However, most of these studies did not explicitly report the type of content, level of complexity, or modality (audio, video, presentation, pictures, assignments, activities, and assessments). Knowledge of the modalities of the content and their associated complexity provides insight into how interventions could be adapted and personalized for patients.

Another notable observation is that several studies (11/31, 35\%) used feedbacks as adaptive elements. Numerous studies described the process of adaptive feedback in different forms, including sending personalized motivational messages [43], tailored messages by therapists $[11,13,54]$, and providing general support [14]. In contrast, a few studies aimed to adapt reminders and alerts by sending an email or SMS text message or making a phone call $[24,48,50]$. Only 2 studies targeted the adaptation of exercises [41,47] and 1 study targeted the adaptation of behavioral activities [60]. We identified a total of 7 papers $(7 / 31$, $23 \%$ ) that adapted assessment tests or psychometric assessment tests $[39,42,45,46,55-57]$. 
Table 3. Types of adaptive elements identified from the relevant studies.

\begin{tabular}{|c|c|}
\hline Main adaptive elements & Study references \\
\hline \multirow[t]{9}{*}{ Intervention content } & Iorfino et al, 2019 [39] \\
\hline & Lagoa et al, 2014 [44] \\
\hline & Batterham et al, 2017 [48] \\
\hline & Rebar et al, 2016 [51] \\
\hline & Coyle et al, 2010 [53] \\
\hline & Nahum-Shani et al, 2012 [12] \\
\hline & Van Gemert-Pijnen et al, 2014 [56] \\
\hline & D'Alfonso et al, 2017 [63] \\
\hline & Kop et al, 2014 [61] \\
\hline Content presentation & Iorfino et al, 2019 [39] \\
\hline \multirow[t]{11}{*}{ Feedback message, support } & Iorfino et al, 2019 [39] \\
\hline & Tielman et al, 2019 [43] \\
\hline & Bannink et al, 2012 [11] \\
\hline & Batterham et al, 2017 [48] \\
\hline & Burns et al, 2011 [50] \\
\hline & Ketelaar et al, 2014 [52] \\
\hline & Malins et al, 2020 [54] \\
\hline & Kitagawa et al, 2019 [13] \\
\hline & Van Gemert-Pijnen et al, 2014 [56] \\
\hline & Dodd et al, 2017 [14] \\
\hline & van de Ven et al, 2017 [32] \\
\hline \multirow[t]{7}{*}{ Assessment tests } & Iorfino et al, 2019 [39] \\
\hline & van Os et al, 2017 [55] \\
\hline & Van Gemert-Pijnen et al, 2014 [56] \\
\hline & Achtyes et al, 2015 [57] \\
\hline & Delgado-Gomez et al, 2016 [42] \\
\hline & Walter et al, 2007 [45] \\
\hline & Eisen et al, 2016 [46] \\
\hline Behavioral activities (sleep pattern) & Erten-Uyumaz et al, 2019 [60] \\
\hline \multirow[t]{3}{*}{ Reminder messages (SMS text messages, emails, phone calls) } & Burns et al, 2011 [50] \\
\hline & Lillevoll et al, 2014 [24] \\
\hline & Batterham et al, 2017 [48] \\
\hline \multirow[t]{2}{*}{ Exercises } & Levin et al, 2018 [41] \\
\hline & Konrad et al, 2015 [47] \\
\hline \multirow[t]{2}{*}{ Reports } & Iorfino et al, 2019 [39] \\
\hline & Burns et al, 2011 [50] \\
\hline Not clear & Tsiakas et al, 2015 [40] \\
\hline
\end{tabular}

Table 3 presents the list of the primary adaptive elements in the adaptive IDPT systems. The list includes (1) intervention content, (2) content presentation, (3) feedback messages, (4) assessment tests, (5) behavioral activities (sleep pattern), (6) reminder messages (email, SMS text messages, phone calls), (7) exercises, and (8) reporting (dashboard for the patients and the therapists). The central concept of adaptiveness is to create different levels of these adaptive elements and provide these elements based on a personalized profile. For example, if a person watches videos more than they listen to audio, read text, or view slides, then based on the principle of adaptiveness, it 
makes sense to present upcoming interventions in a video format.

\section{Dimensions of Adaptation}

The way an adaptive system changes its behaviors depends on a multitude of factors: (1) users' data and preferences, (2) goals of the intervention, (3) measures, (4) adaptation actors, and (5) adaptation strategies. We refer to these aspects as the dimensions of the adaptive IDPT system [28]. Table 4 presents a list of adaptive dimensions extracted from the included studies.

Table 4. Dimensions considered for adaptation in the relevant studies.

\begin{tabular}{|c|c|}
\hline Adaptation dimensions & Study references \\
\hline \multirow[t]{14}{*}{ User data and preferences (user context, needs, and location) } & Iorfino et al, 2019 [39] \\
\hline & Delgado-Gomez et al, 2016 [42] \\
\hline & Tielman et al, 2019 [43] \\
\hline & Lagoa et al, 2014 [44] \\
\hline & Walter et al, 2007 [45] \\
\hline & Eisen et al, 2016 [46] \\
\hline & Van Gemert-Pijnen et al, 2014 [56] \\
\hline & Dodd et al, 2017 [14] \\
\hline & Forsell et al, 2019 [59] \\
\hline & Erten-Uyumaz et al, 2019 [60] \\
\hline & Kop et al, $2014[61]$ \\
\hline & van de Ven et al, 2017 [32] \\
\hline & Rachuri et al, 2010 [62] \\
\hline & D'Alfonso et al, 2017 [63] \\
\hline \multicolumn{2}{|l|}{ Measures } \\
\hline \multirow[t]{15}{*}{ Psychometric tests/screening } & Tsiakas et al, 2015 [40] \\
\hline & Levin et al, 2018 [41] \\
\hline & Bannink et al, 2012 [11] \\
\hline & Batterham et al, 2017 [48] \\
\hline & Berrouiguet et al, 2018 [49] \\
\hline & Burns et al, 2011 [50] \\
\hline & Rebar et al, 2016 [51] \\
\hline & Ketelaar et al, 2014 [52] \\
\hline & Coyle et al, 2010 [53] \\
\hline & Malins et al, 2020 [54] \\
\hline & Nahum-Shani et al, 2012 [12] \\
\hline & Kitagawa et al, 2019 [13] \\
\hline & Van Gemert-Pijnen et al, 2014 [56] \\
\hline & Achtyes et al, 2015 [57] \\
\hline & Wallert et al, 2018 [58] \\
\hline \multirow[t]{2}{*}{ User behavior analysis based on interaction data } & Berrouiguet et al, 2018 [49] \\
\hline & Burns et al, 2011 [50] \\
\hline Goals of intervention & Konrad et al, 2015 [47] \\
\hline \multirow[t]{2}{*}{ Not clear } & van Os et al, 2017 [55] \\
\hline & Lillevoll et al, 2014 [24] \\
\hline
\end{tabular}

The relevant studies were mainly grouped into two clusters based on the choice of adaptive dimensions: user preferences
$(13 / 31,42 \%)$ or outcome measures $(14 / 31,45 \%)$. Only 1 study used a goal-based adaptive dimension. Among the studies using 
user preferences, some studies [32,42-46,62] used user context, while some studies used user location [32,62] to adapt interventions. The studies based on outcome measures used either psychometric tests or user behavior analysis based on interaction data to measure the performance outcome.

\section{Adaptive Strategies}

The adaptive strategy indicates the techniques used to tailor the intervention. In a recent study [28], four significant clusters of adaptive approaches were identified, namely rule-based adaptation, predictive algorithm-based (such as machine learning) adaptation, goal-driven adaptation, and adaptation through a feedback loop. Similar to the study [28], we identified the following adaptive strategies, presented in Table 5, in the reviewed studies.

Table 5. Types of adaptive strategies found in the relevant studies.

\begin{tabular}{|c|c|}
\hline Types of adaptive strategies & Study references \\
\hline \multirow[t]{20}{*}{ Rule-based strategies } & Iorfino et al, 2019 [39] \\
\hline & Tsiakas et al, 2015 [40] \\
\hline & Levin et al, 2018 [41] \\
\hline & Delgado-Gomez et al, 2016 [42] \\
\hline & Tielman et al, 2019 [43] \\
\hline & Walter et al, 2007 [45] \\
\hline & Eisen et al, 2016 [46] \\
\hline & Bannink et al, 2012 [11] \\
\hline & Konrad et al, 2015 [47] \\
\hline & Batterham et al, 2017 [48] \\
\hline & Rebar et al, 2016 [51] \\
\hline & Ketelaar et al, 2014 [52] \\
\hline & Coyle et al, 2010 [53] \\
\hline & Malins et al, 2020 [54] \\
\hline & Nahum-Shani et al, 2012 [12] \\
\hline & Kitagawa et al, 2019 [13] \\
\hline & van Os et al, 2017 [55] \\
\hline & Van Gemert-Pijnen et al, 2014 [56] \\
\hline & Lillevoll et al, 2014 [24] \\
\hline & van de Ven et al, 2017 [32] \\
\hline \multirow[t]{9}{*}{ Predictive algorithm- or machine learning-based strategies } & Tsiakas et al, 2015 [40] \\
\hline & Lagoa et al, 2014 [44] \\
\hline & Berrouiguet et al, 2018 [49] \\
\hline & Burns et al, 2011 [50] \\
\hline & Nahum-Shani et al, 2012 [12] \\
\hline & Wallert et al, 2018 [58] \\
\hline & Rachuri et al, 2010 [62] \\
\hline & Erten-Uyumaz et al, 2019 [60] \\
\hline & Kop et al, 2014 [61] \\
\hline Recommendation-based strategies & D’Alfonso et al, 2017 [63] \\
\hline \multirow[t]{2}{*}{ General or unclear strategy } & Dodd et al, 2017 [14] \\
\hline & Achtyes et al, 2015 [57] \\
\hline
\end{tabular}

The list of strategies includes rule-based strategies, predictive algorithm-based strategies, and recommendation-based strategies. As expected, a significant number of studies (20/31,
$65 \%$ ) used some form of rule-based adaptation mechanism. For example, some studies $[42,45,46]$ used item-response theory [8] to tailor psychometric tests. The primary motivation toward 
adapting psychometric tests is to extract essential information from patients without asking them too many questions. The study by Van Gemert-Pijnen et al [56] applied user behavior analysis by inspecting web-log data and combined it with a rule-based engine to adapt the intervention. The same study concluded that pattern recognition can be a useful tool to tailor interventions based on usage patterns from earlier lessons [56]. With the hype of data science, several studies [12,40,44,49,50,58,60-62] attempted to use some form of predictive algorithm to adapt the intervention. While some studies did not report the outcome of the overall study [40,49], most of them reported that the use of predictive algorithms had a positive effect on the adaptation of interventions [12,44,50,58,60-62]. However, these studies concluded that further research is required to study the effectiveness of performance outcomes.

\section{Efficacy of Treatment Outcomes}

In general, this systematic review shows that tailoring interventions according to patients' needs and preferences has a positive effect on user adherence and hence treatment outcomes. Several studies reported that the personalization of interventions $\quad[13,32,39,41,43,47,50-52,54,56,59] \quad$ and assessments $[42,45,46]$ increased user adherence. Similarly, a study by Coyle et al [53] reported that a personalized system provided a higher degree of user satisfaction. However, some studies reported a lack of noticeable improvement in treatment outcomes. For instance, a study by Batterham et al [48] reported that there was no significant difference between tailored and static versions in the effectiveness of treatment or adherence. However, the same study reported that participants in the tailored conditions were more satisfied than those in the control conditions [48]. Lillevoll et al [24] made a similar conclusion, reporting that tailoring of feedback and dispatching weekly email reminders did not improve the intervention outcomes or user adherence. Given the scenario with two different clusters of results, further research and clinical trials are required to comprehend how user adherence and personalization of interventions are correlated.

\section{Discussion}

\section{Key Findings}

A total of 3341 studies were initially identified based on the inclusion criteria. Following a review of the title, abstract, and full text, 31 studies that fulfilled the inclusion criteria remained, most of which attempted to tailor interventions for mental illnesses. Approximately 68\% (21/31) of the studies had a first author with a health care background. The most common adaptive elements were feedback messages to patients from therapists $(11 / 31,35 \%)$ and intervention content $(9 / 31,29 \%)$. However, how these elements contribute to the efficacy of IDPT in mental illness was not reported. The most common IA used was tunnel-based IA (4/31, 13\%), while many studies (20/31, $65 \%$ ) did not report the IA used. The rule-based technique was the most common adaptive strategy used in these studies (20/31, $65 \%$ ). All the studies were broadly grouped into two adaptive dimensions based on user preferences or using performance measures such as psychometric tests.

\section{Intervention Platform}

Our findings show that web apps, mobile apps, and computer games are the primary platforms used to facilitate interventions. Apart from these, other communication media include robotics, virtual reality (VR) [67], augmented reality (AR), conversational agents, or chatbots [68]. A key finding in the literature study was that most of the IDPTs were made available on mobile apps [69] and web-based apps. This is as expected, as these are the most prevalent platforms used for personal computing. Smartphones contain a plethora of sensors and other data sources that inform aspects of users' well-being, context, activities, behaviors, and intentions. However, only a few attempts have been made to provide IDPT using conversational agents [68], or VR or AR apps. As depicted in Figure 2, higher placement in the chain indicates higher computational complexity but lower prevalence. Conversely, lower placement in the chain indicates lower computational complexity but higher prevalence. The most obvious explanation for the selection of web and mobile apps for intervention platforms is their prevalence. It makes the most sense to develop for platforms that are being used the most. 
Figure 2. Mode of delivery for internet-delivered psychological treatments (IDPTs). AR: augmented reality; mHealth: mobile health; VR: virtual reality.

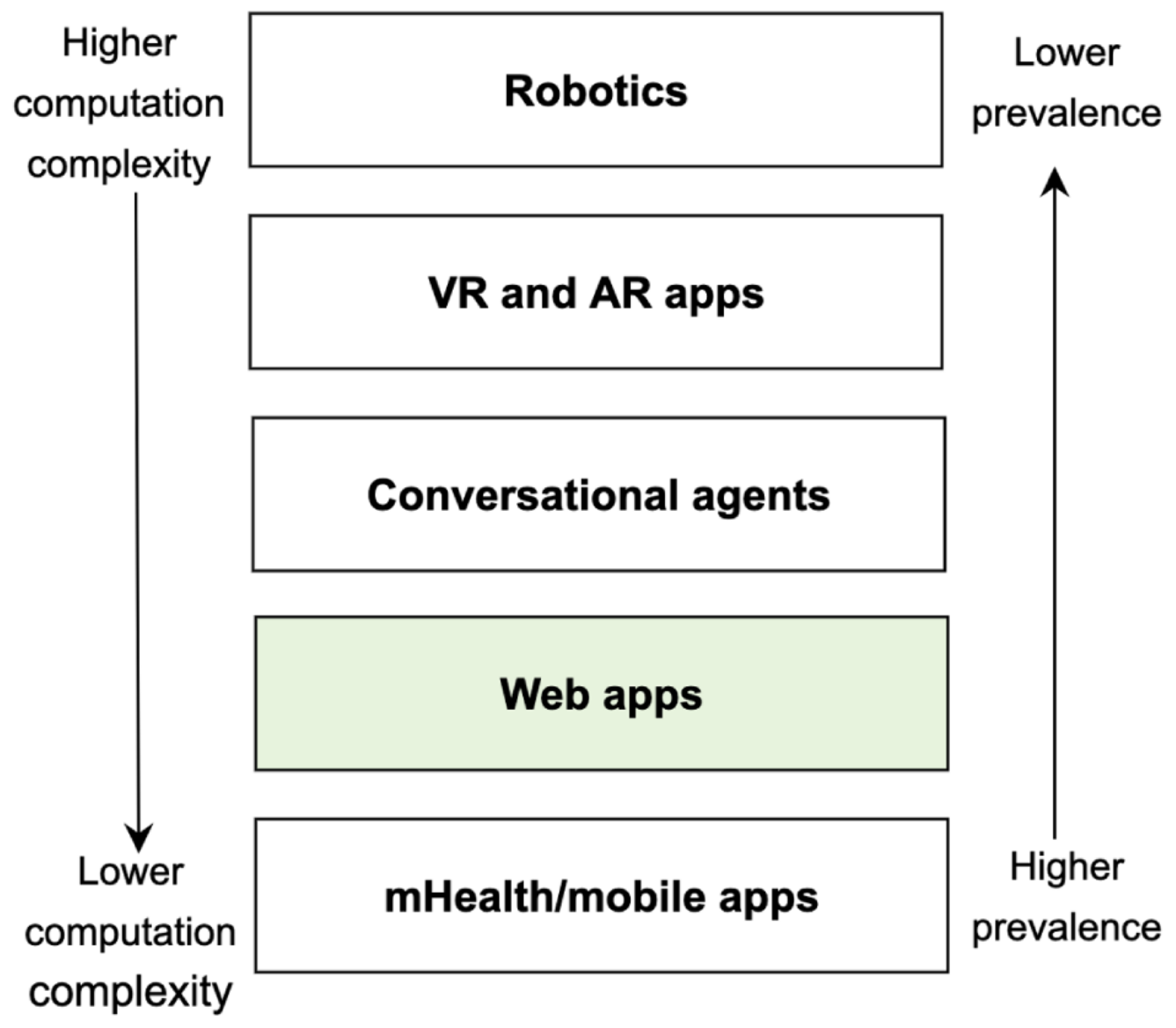

\section{IA}

Although a significant number of the studies failed to report which IA was used in their IDPT system, IA is still present in all software systems. Understanding the IA of a system helps a user to store, find, and interpret information readily, as IA is the design principle that is applied to making information discoverable and understandable. Finding the underlying IA of the IDPT system can help in making systems accessible and discoverable for end users, and knowledge about information design, structure, organization, and labelling can facilitate the development and evaluation phase. As explained in a previous study [70], IA consists of three major components: user, content, and context. Hence, IA helps to discover content for users based on their context. Assisting users with the correct piece of information they are looking for can increase user adherence by reducing bounce rate [71] and hence improve treatment outcomes. While our findings show most of the current adaptive IDPT systems are tunnel-based and don't promote personalization, we promote the use of hierarchical IA or hybrid IA in order to present useful information according to patients' needs and argue that the latter designs offer richer opportunities for adaptive IDPT systems.

\section{Adaptive Elements}

The primary context for building adaptive IDPT systems is to assist patients suffering from mental health disorders to learn about and recover from their illnesses. An IDPT system provides this information by using different media and elements such as text, video, audio, pictures, presentations, feedback, reminders, reports, and others. These elements have their format, structure, metadata, volume, and dynamism (such as frequency of updates). It is essential to understand these elements (contents described by Pakkala et al [71]) and the associated attributes in order to deliver the correct content to the right user in their current context. For example, understanding the complexity of the text describing sleep disorders can help to personalize the content based on the educational background of the patients. A general assumption is that an educated person can comprehend more complex language and medical terms than a nonspecialist. For a nonspecialist, it is more valuable to present the same content in terms of animated videos or pictures.

\section{Adaptive Dimensions}

The adaptive dimension provides the context for an adaptive IDPT system to tailor its behavior. A common way to tailor the behavior of the IDPT system is based on input regarding user preferences, measures (psychometric tests, user behavior analysis, and others), and goals, as shown in Table 4. In the context of user preferences, a study by Yardley et al [72] outlined that users can feel overwhelmed by the quantity and complexity of information presented to them. Hence, it is advisable to meet the needs of different users based on their needs and preferences. Personalization is critical mainly because users have different cognitive skills, educational backgrounds, content format preferences, comprehension capabilities, and 
other qualities. A similar conclusion was made by Sundar and Marathe [73]. Their study identified two types of users: those influenced more by the affordance of agency (power users) and those influenced by the relevancy of the resulting content. The results of the study revealed that nonpower users preferred personalized content, whereas power users rated content quality higher when the website had a customizable feature. Similar to user preferences, other dimensions of adaption are performance measures such as the use of psychometric tests (eg, Patient Health Questionnaire-9 [74] for depression), user behavior analysis, and others.

\section{Adaptive Strategies}

Adaptive strategies provide a mechanism to present the right content to the right people based on their needs and preferences. While our review findings reveal that the rule-based adaptive strategy is the most widely adopted practice, other strategies, especially machine learning, are becoming highly prevalent. Given the premise that we can capture every digital footprint of a user, resulting in a complex and comprehensive data set, there is a possibility of using sophisticated machine learning or deep learning algorithms on the one hand, but it also raises an essential question about privacy on the other. In general, to build an adaptive IDPT system, it is crucial to understand which adaptive strategies can be used. Based on the selected strategies, one needs to collect and store the data. No matter which adaptive strategy is chosen, the adaption in an IDPT system is an iterative cycle where data is collected and preprocessed; preprocessed data are then analyzed and, based on the results of the analysis, an action is taken to tailor the intervention. However, how the data are analyzed and the result is extracted affect the way an IDPT system is developed, the choice of IA, the method of data storage, and other parameters.

\section{Challenges in Contemporary IDPT Systems}

Although the integration of health care systems has emerged as a policy for several health care agencies, there is a large gap between current policy, program implementation efforts, and evidence for health care integration. The results of our review led us to list the following challenges in current IDPT practice.

\section{Lack of Standard Taxonomy in IDPT}

There is a lack of a standardized definition of the health care system and proper taxonomy to allow the grouping of similar interventions. As mentioned in the introduction, the use of nonstandard terms to refer to the same system causes inconsistencies and makes it hard to draw conclusions. Based on this challenge, several researchers [75-77] have made an effort to formalize the health care system to support interoperability [76], such as the Fast Healthcare Interoperability Resources (FHIR) created by the Health Level Seven International (HL7) health care standards organization [78] and others. If there is a standard followed by researchers for building adaptive IDPT systems, it will become easier to learn from their findings and extend the current understanding to improve treatment outcomes.

\section{Scientific Foundation}

The outcome of trials of IDPT systems has demonstrated comparable results as face-to-face therapies. However, despite considerable attention to IDPTs, user adherence is low, and there is remarkably less literature on the underlying science of the field of IDPT system design and development [79]. Many pieces of literature claim IDPT to be based on psychoeducation that helps in the modification of behavior change and symptom improvement. While this assumption may be correct, the underlying science behind how psychoeducation about particular symptoms enhances behavior modifications and symptom improvement is less evident in the literature. Lack of a scientific foundation behind IDPT systems may be the reason behind users' lack of trust toward interventions [21-23] and hence lack of adherence. In the same way, an IDPT system is an application software that follows an IA (see Table 2) and design patterns [80]. The application software such as IDPT are well formalized and studied in the research community. Lack of such reporting makes it challenging to conclude how adaptive elements or the IA influence the outcome of an intervention.

\section{Ethical and Safety Issues Associated with Predictive Adaptive Strategies}

Technology has matured to the point where several researchers envision the creation of automated, adaptive IDPT systems that work without much human involvement. However, there are controversies between what is possible and what is acceptable in adaptive systems. Hence, it requires careful consideration of both ethical and legal issues; focusing solely on technological and operational perspectives can lead to low value or utility for patients. As a result, both information and communication technology (ICT) researchers and medical practitioners must consider the capabilities, limitations, and needs of patients when designing adaptive systems. The primary objective of the adaptive IDPT system is to tailor the intervention based on user needs or any other adaptive dimensions. The adaptive IDPT system can understand the user's needs by creating detailed user profiling. User profiling includes storage of the patient's previous diagnosis, sensitive personal information, as well as the current status. Moreover, to maximize the benefits of data-driven adaptiveness, the adaptive IDPT system needs to store interaction data, including the time of login, the frequency of login, and the interaction with the system at the granular level (clicks, keystrokes). For example, the study by Van Gemert-Pijnen [56] analyzed the log data in order to understand the use of the content. Storing such user interaction data requires proper user consent on the one hand and directly deals with the privacy of the patient on the other. Hence, it is one of the critical challenges in the development of an adaptive IDPT system. It requires further research into the problem of storing user interaction data securely. For example, many psychological interventions aim to characterize patients' symptoms based on their mobile phone usage. This type of study is possible because mobile phones come with built-in sensors and standard application programming interfaces to measure and collect patients' data, including mobility patterns, physical activities, crowd density, time spent indoors versus outdoors, and locations. Although these capabilities are possible with the advances in ubiquitous computing, they deal directly with privacy and ethical issues. 


\section{Implications and Future Directions}

It is not easy to predict how technologies will develop over time and whether these technologies will continue adapting to clinical use. However, based on the results of this systematic review, we outline some implications and future directions in the field of IDPT system development and innovation.

\section{Implications for ICT Researchers}

With an increasing trend in user adherence toward internet-delivered treatments on the one hand and the prevalence of the internet of things (IoT), with growth in ambient intelligence technology, on the other, there is an expectation that the IDPT system will flourish over time. A plethora of health care interventions delivered via the internet have a similar format, as most of them are based on psychoeducation. All such interventions attempt to create adaptive elements (see Table 3) and attempt to tailor these elements based on adaptive dimensions (see Table 4) using adaptive strategies (see Table 5). Hence, it makes sense to create a conceptual framework that can be utilized in several health care domains. Moreover, the creation of domain-specific languages for incorporating adaptive health care interventions is also required. We also need better dashboard tools that help therapists and other medical practitioners to comprehend patients' status better and adapt their interventions based on their engagement with the interventions.

We analyzed the state-of-the-art studies concerned with adapting psychological interventions. The analysis yielded the answers to the most critical questions, including (1) what are the essential elements that therapists wish to tailor? (2) what are the main dimensions in which these elements can be tailored to meet patients' needs? and (3) what are the primary adaptive strategies used to trigger adaptation in those dimensions? Findings from the analysis helped to identify the essential variables that are associated with an adaptive system. As McGaghie et al [81] outlined, once ICT researchers and developers know the essential variables, they can utilize these findings to create a conceptual framework that sets the stage for the presentation of a particular problem, which in this case is the creation of an adaptive IDPT system. Further, ICT researchers and developers can validate the conceptual framework by building domain-specific language.

\section{Implication for Health Care Researchers}

While the current research evidence is fragmented about the benefit of an adaptive IDPT system on treatment outcomes, this review suggests that adaptive IDPT systems can benefit people with mental health issues in providing personalized psychoeducation. Such an education will help mental health patients to manage their illness. In addition, a high number of health care researchers have published about adaptive interventions, as shown in Figure 2. This indicates that both health care researchers and computer researchers believe that adaptive interventions are an essential phenomenon to accelerate user adherence. However, tailoring the feedbacks given by therapists or providing reminders are simple forms of adaptation (see Table 3). The intervention can be adapted for several dimensions, including user preferences, outcome measures, and different adaptive strategies [28], with the amalgamation of ambient technology. Hence, cooperation between ICT and health care researchers is essential to develop an adaptive IDPT system. While more randomized controlled trials are required to validate the effectiveness of adaptive treatments, the results of this review show sufficient evidence to suggest that the adaptation of mental health interventions can enhance user adherence and treatment outcomes.

\section{Implication for Computer Science Research}

The development of an adaptive IDPT system that increases user adherence and treatment outcomes requires more extensive research to establish clinical appropriateness. Given the potential benefit of the IDPT system for cost-effective delivery to the far-reaching population, further research should be conducted on how to personalize adaptive strategies. Furthermore, reporting back to the research community is the part of any discipline of transparency that keeps studies honest and accountable. In addition, it fits into the broader responsibilities of scientists to communicate their work and foster public understanding. Such understanding can be used by other researchers to gain insight into new research directions.

\section{Future Work}

An immediate future task involves the creation of a conceptual framework for adaptive IDPT systems. In addition to this, we envision the development of domain-specific language that can model such an adaptive IDPT system. Furthermore, it is imperative from the review that there is a need for a comprehensive visual dashboard for therapists and patients where they can receive the intervention, monitor their symptoms, and manage their illness.

\section{Limitations}

Given that the health ICT literature is quite diverse and extensive, the current study focused exclusively on internet-delivered interventions for mental health morbidities. Notwithstanding this limitation, this paper highlights the significance of the continued study of this intervention method. Another limitation is that our literature exploration only encompassed articles in the English language; therefore, it is plausible that some research conducted in other parts of the world and published in other languages were missed. A third limitation pertains to IDPT apps developed by industry that were not accessible for review. Hence, we have less knowledge about the adaptive elements involved in their architecture.

\section{Conclusions}

Adaptive psychological interventions tailor the type of content or tasks to individuals based on their needs and preferences in order to improve saliency and intervention efficacy. This systematic review describes the investigation and analysis of existing studies about adaptive psychological intervention delivered through the internet. The study outlines the main elements used in the process of adaptation, the IA used in the adaptive systems, the main dimensions of adaptation, and the main adaptive strategies. Based on these findings, we envision the development of a conceptual framework that researchers and clinicians can utilize to build adaptive models of several health care interventions. 
The findings of our review indicate the use of web-based and mobile apps to deliver mental health interventions, such as for depression (most studied), anxiety, and others. However, a number of these studies did not report the IA used in their system, and those that did report mostly used tunnel-based systems. Similarly, several studies used rule-based adaptive strategies to adapt intervention based on performance measures such as psychometric tests. Feedback messages, reminders, and support were the most used adaptive element. Further study is required to explore the role of IA, adaptive elements, adaptive dimensions, and adaptive strategies in building a successful IDPT system. Knowledge about these core elements of the adaptive IDPT system can serve to create a conceptual framework that can be used for several health care interventions.

\section{Acknowledgments}

We owe a lot of thanks and gratitude to our colleagues for their help searching for publications, refining articles and cross-referencing the relevant papers. This publication is a part of the INTROducing Mental health through Adaptive Technology (INTROMAT) project (www.intromat.no), funded by the Norwegian Research Council (259293/o70). INTROMAT is a research and development project in Norway that employs adaptive technology for confronting mental health issues.

\section{Conflicts of Interest}

None declared.

\section{Multimedia Appendix 1}

Search terms that were used to execute the search in different databases.

[PDF File (Adobe PDF File), 90 KB-Multimedia Appendix 1]

\section{Multimedia Appendix 2}

The main table that helped to extract the adaptive elements, adaptive strategies, information architecture, and other information about the internet-delivered psychological treatment system.

[XLSX File (Microsoft Excel File), 68 KB-Multimedia Appendix 2]

\section{References}

1. Portnoy D, Scott-Sheldon LAJ, Johnson BT, Carey MP. Computer-delivered interventions for health promotion and behavioral risk reduction: a meta-analysis of 75 randomized controlled trials, 1988-2007. Prev Med 2008 Jul;47(1):3-16 [FREE Full text] [doi: 10.1016/j.ypmed.2008.02.014] [Medline: 18403003]

2. Marks IM, Cavanagh K, Gega L. Computer-aided psychotherapy: revolution or bubble? Br J Psychiatry 2018 Jan 02;191(6):471-473 [FREE Full text] [doi: 10.1192/bjp.bp.107.041152]

3. Wallin EEK, Mattsson S, Olsson EMG. The Preference for Internet-Based Psychological Interventions by Individuals Without Past or Current Use of Mental Health Treatment Delivered Online: A Survey Study With Mixed-Methods Analysis. JMIR Ment Health 2016 Jun 14;3(2):e25 [FREE Full text] [doi: 10.2196/mental.5324] [Medline: 27302200]

4. Bennett G, Glasgow RE. The delivery of public health interventions via the Internet: actualizing their potential. Annu Rev Public Health 2009;30:273-292 [FREE Full text] [doi: 10.1146/annurev.publhealth.031308.100235] [Medline: 19296777]

5. Eysenbach G. The law of attrition. J Med Internet Res 2005 Mar 31;7(1):e11 [FREE Full text] [doi: 10.2196/jmir.7.1.e11] [Medline: 15829473 ]

6. Dunn T, Casey LM, Sheffield J, Newcombe P, Chang AB. Dropout from computer-based interventions for children and adolescents with chronic health conditions. J Health Psychol 2012 Apr;17(3):429-442 [FREE Full text] [doi: 10.1177/1359105311415558] [Medline: 21890540]

7. Christensen H, Griffiths KM, Farrer L. Adherence in internet interventions for anxiety and depression. J Med Internet Res 2009 Apr 24;11(2):e13 [FREE Full text] [doi: 10.2196/jmir.1194] [Medline: 19403466]

8. Fraley R, Waller N, Brennan K. An item response theory analysis of self-report measures of adult attachment. Journal of Personality and Social Psychology 2000;78(2):350-365 [FREE Full text] [doi: 10.1037/0022-3514.78.2.350]

9. Andersson G. Using the Internet to provide cognitive behaviour therapy. Behav Res Ther 2009 Mar;47(3):175-180 [FREE Full text] [doi: $\underline{10.1016 / j . b r a t .2009 .01 .010]}$ [Medline: 19230862$]$

10. Spek V, Cuijpers P, Nyklícek I, Riper H, Keyzer J, Pop V. Internet-based cognitive behaviour therapy for symptoms of depression and anxiety: a meta-analysis. Psychol Med 2007 Mar 20;37(3):319-328 [FREE Full text] [doi: 10.1017/S0033291706008944] [Medline: 17112400]

11. Bannink R, Joosten-van Zwanenburg E, van de Looij-Jansen P, van As E, Raat H. Evaluation of computer-tailored health education ('E-health4Uth') combined with personal counselling ('E-health4Uth + counselling') on adolescents' behaviours and mental health status: design of a three-armed cluster randomised controlled trial. BMC Public Health 2012 Dec 17;12:1083 [FREE Full text] [doi: 10.1186/1471-2458-12-1083] [Medline: 23244449] 
12. Nahum-Shani I, Qian M, Almirall D, Pelham WE, Gnagy B, Fabiano GA, et al. Q-learning: a data analysis method for constructing adaptive interventions. Psychol Methods 2012 Dec;17(4):478-494 [FREE Full text] [doi: 10.1037/a0029373] [Medline: 23025434]

13. Kitagawa T, Higuchi Y, Todo E, Ueda T, Ando S, Murakami T. Tailored feedback reduced prolonged sitting time and improved the health of housewives: a single-blind randomized controlled pilot study. Women \& Health 2019 May 21;60(2):212-223 [FREE Full text] [doi: 10.1080/03630242.2019.1616043]

14. Dodd A, Mallinson S, Griffiths M, Morriss R, Jones SH, Lobban F. Users' experiences of an online intervention for bipolar disorder: important lessons for design and evaluation. Evid Based Ment Health 2017 Nov;20(4):133-139 [FREE Full text] [doi: 10.1136/eb-2017-102754] [Medline: 29061886]

15. Clarke G, Eubanks D, Reid E, Kelleher C, O'Connor E, DeBar LL, et al. Overcoming Depression on the Internet (ODIN) (2): a randomized trial of a self-help depression skills program with reminders. J Med Internet Res 2005 Jun 21;7(2):e16 [FREE Full text] [doi: 10.2196/jmir.7.2.e16] [Medline: 15998607]

16. Farrer L, Christensen H, Griffiths KM, Mackinnon A. Internet-based CBT for depression with and without telephone tracking in a national helpline: randomised controlled trial. PLoS One 2011;6(11):e28099 [FREE Full text] [doi: 10.1371/journal.pone.0028099] [Medline: 22140514]

17. Klein B, Austin D, Pier C, Kiropoulos L, Shandley K, Mitchell J, et al. Internet-based treatment for panic disorder: does frequency of therapist contact make a difference? Cogn Behav Ther 2009;38(2):100-113 [FREE Full text] [doi: 10.1080/16506070802561132] [Medline: 19306149 ]

18. Hilvert-Bruce Z, Rossouw PJ, Wong N, Sunderland M, Andrews G. Adherence as a determinant of effectiveness of internet cognitive behavioural therapy for anxiety and depressive disorders. Behav Res Ther 2012 Aug;50(7-8):463-468 [FREE Full text] [doi: 10.1016/j.brat.2012.04.001] [Medline: 22659155]

19. Bewick B, Trusler K, Mulhern B, Barkham M, Hill AJ. The feasibility and effectiveness of a web-based personalised feedback and social norms alcohol intervention in UK university students: a randomised control trial. Addict Behav 2008 Sep;33(9):1192-1198 [FREE Full text] [doi: 10.1016/j.addbeh.2008.05.002] [Medline: 18554819]

20. Vandereycken W, Devidt K. Dropping out from a specialized inpatient treatment for eating disorders: the perception of patients and staff. Eat Disord 2010;18(2):140-147 [FREE Full text] [doi: 10.1080/10640260903585557] [Medline: 20390617]

21. Johansson O, Michel T, Andersson G, Paxling B. Experiences of non-adherence to Internet-delivered cognitive behavior therapy: A qualitative study. Internet Interventions 2015 May;2(2):137-142 [FREE Full text] [doi:

10.1016/j.invent.2015.02.006]

22. Sledge W, Moras K, Hartley D, Levine M. Effect of time-limited psychotherapy on patient dropout rates. Am J Psychiatry 1990 Oct;147(10):1341-1347 [FREE Full text] [doi: 10.1176/ajp.147.10.1341] [Medline: 2400003]

23. El Alaoui S, Ljótsson B, Hedman E, Kaldo V, Andersson E, Rück C, et al. Predictors of Symptomatic Change and Adherence in Internet-Based Cognitive Behaviour Therapy for Social Anxiety Disorder in Routine Psychiatric Care. PLoS One 2015;10(4):e0124258 [FREE Full text] [doi: 10.1371/journal.pone.0124258] [Medline: 25893687]

24. Lillevoll K, Vangberg HCB, Griffiths KM, Waterloo K, Eisemann MR. Uptake and adherence of a self-directed internet-based mental health intervention with tailored e-mail reminders in senior high schools in Norway. BMC Psychiatry 2014 Jan 21;14:14 [FREE Full text] [doi: 10.1186/1471-244X-14-14] [Medline: 24443820]

25. Doherty G, Coyle D, Sharry J. Engagement with online mental health interventions: an exploratory clinical study of a treatment for depression. In: CHI '12: Proceedings of the SIGCHI Conference on Human Factors in Computing Systems. USA: Association for Computing Machinery, New York, NY, United States; 2012 May Presented at: In Proceedings of the SIGCHI Conference on Human Factors in Computing Systems; May, 2012; Austin Texas USA p. 1421-1430 URL: https://doi.org/10.1145/2207676.2208602 [doi: 10.1145/2207676.2208602]

26. Garfield SL, Bergin AE, Dryden W. Handbook of Psychotherapy and Behavior Change. The influence of client variables on psychotherapy. Bergin and Garfield?s 1987 Jan 01;1(4):264.2-26265. [doi: 10.1891/0889-8391.1.4.264a]

27. World Health Organization, WHO. Adherence to long-term therapies: evidence for action. In: In ADHERENCE TO LONG-TERM THERAPIES: Evidence for action (p. 211). USA: World Health Organization; 2003.

28. Mukhiya SK, Wake JD, Inal Y, Lamo Y. Adaptive Systems for Internet-Delivered Psychological Treatments. IEEE Access 2020;8:112220-112236. [doi: 10.1109/access.2020.3002793]

29. Danaher BG, Brendryen H, Seeley JR, Tyler MS, Woolley T. From black box to toolbox: Outlining device functionality, engagement activities, and the pervasive information architecture of mHealth interventions. Internet Interventions 2015 Mar;2(1):91-101 [FREE Full text] [doi: 10.1016/j.invent.2015.01.002]

30. Lange A, Rietdijk D, Hudcovicova M, van de Ven JP, Schrieken B, Emmelkamp PMG. Interapy: a controlled randomized trial of the standardized treatment of posttraumatic stress through the internet. J Consult Clin Psychol 2003 Oct;71(5):901-909. [doi: 10.1037/0022-006X.71.5.901] [Medline: 14516238]

31. Meyer B, Berger T, Caspar F, Beevers CG, Andersson G, Weiss M. Effectiveness of a novel integrative online treatment for depression (Deprexis): randomized controlled trial. J Med Internet Res 2009 May 11;11(2):e15 [FREE Full text] [doi: 10.2196/jmir.1151] [Medline: 19632969] 
32. van de Ven P, O'Brien H, Henriques R, Klein M, Msetfi R, Nelson J, E-COMPARED Consortium. ULTEMAT: A mobile framework for smart ecological momentary assessments and interventions. Internet Interv 2017 Sep;9:74-81 [FREE Full text] [doi: 10.1016/j.invent.2017.07.001] [Medline: $\underline{\text { 30135840] }}$

33. Pejovic V, Musolesi M. Anticipatory mobile computing for behaviour change interventions. In: UbiComp '14 Adjunct: Proceedings of the 2014 ACM International Joint Conference on Pervasive and Ubiquitous Computing: Adjunct Publication. New York, NY: Association for Computing Machinery; 2014 Sep Presented at: Anticipatory mobile computing for behaviour change interventions. In UbiComp - Adjunct Proceedings of the ACM International Joint Conference on Pervasive and Ubiquitous Computing (pp. 1025?1034). Association for Computing Machinery, Inc; 2014; Seattle Washington, USA p. 1025-1034 URL: https://doi.org/10.1145/2638728.2641284 [doi: 10.1145/2638728.2641284]

34. Donker T, Petrie K, Proudfoot J, Clarke J, Birch M, Christensen H. Smartphones for smarter delivery of mental health programs: a systematic review. J Med Internet Res 2013 Nov 15;15(11):e247 [FREE Full text] [doi: 10.2196/jmir.2791] [Medline: 24240579]

35. Andersson G, Titov N, Dear BF, Rozental A, Carlbring P. Internet-delivered psychological treatments: from innovation to implementation. World Psychiatry 2019 Feb;18(1):20-28 [FREE Full text] [doi: 10.1002/wps.20610] [Medline: 30600624$]$

36. Moher D, Shamseer L, Clarke M, Ghersi D, Liberati A, Petticrew M, PRISMA-P Group. Preferred reporting items for systematic review and meta-analysis protocols (PRISMA-P) 2015 statement. Syst Rev 2015 Jan 01;4:1 [FREE Full text] [doi: 10.1186/2046-4053-4-1] [Medline: 25554246]

37. Furlan AD, Pennick V, Bombardier C, van Tulder M, Editorial Board, Cochrane Back Review Group. 2009 updated method guidelines for systematic reviews in the Cochrane Back Review Group. Spine (Phila Pa 1976) 2009 Aug 15;34(18):1929-1941. [doi: 10.1097/BRS.0b013e3181b1c99f] [Medline: 19680101]

38. American Psychiatric Association, APA. American Psychiatric Association, 2013. In: Diagnostic and statistical manual of mental disorders (5th ed). USA: American Psychiatric Association; May 2013.

39. Iorfino F, Cross SP, Davenport T, Carpenter JS, Scott E, Shiran S, et al. A Digital Platform Designed for Youth Mental Health Services to Deliver Personalized and Measurement-Based Care. Front Psychiatry 2019;10:595 [FREE Full text] [doi: 10.3389/fpsyt.2019.00595] [Medline: 31507465]

40. Tsiakas K, Watts L, Lutterodt C, Giannakopoulos T, Papangelis A, Gatchel R, et al. A multimodal adaptive dialogue manager for depressive and anxiety disorder screening: a Wizard-of-Oz experiment. In: PETRA '15: Proceedings of the 8th ACM International Conference on PErvasive Technologies Related to Assistive Environments. 2015 Jul Presented at: PETRA '15: Proceedings of the 8th ACM International Conference on Pervasive Technologies Related to Assistive Environments; July, 2015; Corfu Greece p. 1-4 URL: https://doi.org/10.1145/2769493.2769572 [doi: 10.1145/2769493.2769572]

41. Levin M, Navarro C, Cruz RA, Haeger J. Comparing in-the-moment skill coaching effects from tailored versus non-tailored acceptance and commitment therapy mobile apps in a non-clinical sample. Cogn Behav Ther 2019 May;48(3):200-216 [FREE Full text] [doi: 10.1080/16506073.2018.1503706] [Medline: 30117784]

42. Delgado-Gomez D, Baca-Garcia E, Aguado D, Courtet P, Lopez-Castroman J. Computerized Adaptive Test vs. decision trees: Development of a support decision system to identify suicidal behavior. J Affect Disord 2016 Dec;206:204-209 [FREE Full text] [doi: 10.1016/j.jad.2016.07.032] [Medline: 27475891]

43. Tielman M, Neerincx MA, Brinkman WP. Design and Evaluation of Personalized Motivational Messages by a Virtual Agent that Assists in Post-Traumatic Stress Disorder Therapy. J Med Internet Res 2019 Mar 27;21(3):e9240 [FREE Full text] [doi: 10.2196/jmir.9240] [Medline: 30916660]

44. Lagoa C, Bekiroglu K, Lanza ST, Murphy SA. Designing adaptive intensive interventions using methods from engineering. J Consult Clin Psychol 2014 Oct;82(5):868-878 [FREE Full text] [doi: 10.1037/a0037736] [Medline: 25244394]

45. Walter O, Becker J, Bjorner JB, Fliege H, Klapp BF, Rose M. Development and evaluation of a computer adaptive test for 'Anxiety' (Anxiety-CAT). Qual Life Res 2007;16 Suppl 1:143-155. [doi: 10.1007/s11136-007-9191-7] [Medline: 17342455]

46. Eisen S, Schultz MR, Ni P, Haley SM, Smith EG, Spiro A, et al. Development and Validation of a Computerized-Adaptive Test for PTSD (P-CAT). Psychiatr Serv 2016 Oct 01;67(10):1116-1123 [FREE Full text] [doi: 10.1176/appi.ps.201500382] [Medline: 27247175]

47. Konrad A, Bellotti V, Crenshaw N, Tucker S, Nelson L, Du H, et al. Finding the Adaptive Sweet Spot: Balancing Compliance and Achievement in Automated Stress Reduction. New York, NY: Association for Computing Machinery; 2015 Apr Presented at: CHI '15: Proceedings of the 33rd Annual ACM Conference on Human Factors in Computing Systems; April, 2015; Seoul Republic of Korea p. 3829-3838 URL: https://doi.org/10.1145/2702123.2702512 [doi: 10.1145/2702123.2702512]

48. Batterham P, Calear AL, Farrer L, McCallum SM, Cheng VWS. : Randomised controlled trial of an automatically tailored online program for mood, anxiety, substance use and suicidality. Internet Interv 2018 Jun; 12:91-99 [FREE Full text] [doi: 10.1016/j.invent.2017.08.002] [Medline: 30135773]

49. Berrouiguet S, Perez-Rodriguez MM, Larsen M, Baca-García E, Courtet P, Oquendo M. From eHealth to iHealth: Transition to Participatory and Personalized Medicine in Mental Health. J Med Internet Res 2018 Jan 03;20(1):e2 [FREE Full text] [doi: 10.2196/jmir.7412] [Medline: 29298748] 
50. Burns M, Begale M, Duffecy J, Gergle D, Karr CJ, Giangrande E, et al. Harnessing context sensing to develop a mobile intervention for depression. J Med Internet Res 2011 Aug 12;13(3):e55 [FREE Full text] [doi: 10.2196/jmir.1838] [Medline: 21840837]

51. Rebar A, Boles C, W. Burton N, Duncan M, Short C, Happell B, et al. Healthy mind, healthy body: A randomized trial testing the efficacy of a computer-tailored vs. interactive web-based intervention for increasing physical activity and reducing depressive symptoms. Mental Health and Physical Activity 2016 Oct;11:29-37 [FREE Full text] [doi: 10.1016/j.mhpa.2016.08.001]

52. Ketelaar S, Nieuwenhuijsen K, Bolier L, Smeets O, Sluiter JK. Improving work functioning and mental health of health care employees using an e-mental health approach to workers' health surveillance: pretest-posttest study. Saf Health Work 2014 Dec;5(4):216-221 [FREE Full text] [doi: 10.1016/j.shaw.2014.08.002] [Medline: 25516815]

53. Coyle D, Doherty G, Sharry J. PlayWrite: end-user adaptable games to support adolescent mental health. New York, NY: Association for Computing Machinery; 2010 Apr Presented at: CHI EA '10: CHI '10 Extended Abstracts on Human Factors in Computing Systems; April, 2010; Atlanta Georgia USA p. 3889-3894 URL: https://doi.org/10.1145/1753846.1754074 [doi: $10.1145 / 1753846.1754074]$

54. Malins S, Biswas S, Patel S, Levene J, Moghaddam N, Morriss R. Preventing relapse with personalized smart-messaging after cognitive behavioural therapy: A proof-of-concept evaluation. Br J Clin Psychol 2020 Jun 20;59(2):241-259 [FREE Full text] [doi: 10.1111/bjc.12244] [Medline: 31960467]

55. van Os J, Verhagen S, Marsman A, Peeters F, Bak M, Marcelis M, ESM-MERGE Investigators PhD, et al. The experience sampling method as an mHealth tool to support self-monitoring, self-insight, and personalized health care in clinical practice. Depress Anxiety 2017 Jun;34(6):481-493 [FREE Full text] [doi: 10.1002/da.22647] [Medline: 28544391]

56. Van Gemert-Pijnen JE, Kelders SM, Bohlmeijer ET. Understanding the usage of content in a mental health intervention for depression: an analysis of log data. J Med Internet Res 2014 Jan 31;16(1):e27 [FREE Full text] [doi: 10.2196/jmir.2991] [Medline: 24486914]

57. Achtyes E, Halstead S, Smart L, Moore T, Frank E, Kupfer DJ, et al. Validation of Computerized Adaptive Testing in an Outpatient Nonacademic Setting: The VOCATIONS Trial. Psychiatr Serv 2015 Oct;66(10):1091-1096 [FREE Full text] [doi: 10.1176/appi.ps.201400390] [Medline: 26030317]

58. Wallert J, Gustafson E, Held C, Madison G, Norlund F, von Essen L, et al. Predicting Adherence to Internet-Delivered Psychotherapy for Symptoms of Depression and Anxiety After Myocardial Infarction: Machine Learning Insights From the U-CARE Heart Randomized Controlled Trial. J Med Internet Res 2018 Oct 10;20(10):e10754 [FREE Full text] [doi: 10.2196/10754] [Medline: 30305255]

59. Forsell E, Jernelöv S, Blom K, Kraepelien M, Svanborg C, Andersson G, et al. Proof of Concept for an Adaptive Treatment Strategy to Prevent Failures in Internet-Delivered CBT: A Single-Blind Randomized Clinical Trial With Insomnia Patients. Am J Psychiatry 2019 Apr 01;176(4):315-323 [FREE Full text] [doi: 10.1176/appi.ajp.2018.18060699] [Medline: 30696270]

60. Erten-Uyumaz B, Ahuja M, Vacaretu T, Rama MD, Overeem S, Visser T, et al. Design and evaluation of a negotiation-based sleep scheduler app for insomnia treatment. New York, NY: Association for Computing Machinery; 2019 May Presented at: Pervasive Health'19: Proceedings of the 13th EAI International Conference on Pervasive Computing Technologies for Healthcare; May, 2019; Trento Italy p. 225-233 URL: https://doi.org/10.1145/3329189.3329218 [doi: $10.1145 / 3329189.3329218]$

61. Kop R, Hoogendoorn M, Klein CAM. A Personalized Support Agent for Depressed Patients: Forecasting Patient Behavior Using a Mood and Coping Model. : 2014 IEEE/WIC/ACM International Joint Conferences on Web Intelligence (WI) and Intelligent Agent Technologies (IAT); 2014 Presented at: IEEE WIC ACM International Conference on Web Intelligence (WI); 11-14 Aug. 2014; Warsaw, Poland URL: https://doi.org/10.1109/WI-IAT.2014.181 [doi: 10.1109/wi-iat.2014.181]

62. Rachuri K, Musolesi M, Mascolo C, Rentfrow P, Longworth C, Aucinas A. EmotionSense: a mobile phones based adaptive platform for experimental social psychology research. New York, NY: Association for Computing Machinery; 2010 Sep Presented at: UbiComp '10: Proceedings of the 12th ACM international conference on Ubiquitous computing; September 2010; Copenhagen Denmark p. 281-290 URL: https://doi.org/10.1145/1864349.1864393 [doi: 10.1145/1864349.1864393]

63. D'Alfonso S, Santesteban-Echarri O, Rice S, Wadley G, Lederman R, Miles C, et al. Artificial Intelligence-Assisted Online Social Therapy for Youth Mental Health. Front Psychol 2017;8:796 [FREE Full text] [doi: 10.3389/fpsyg.2017.00796] [Medline: 28626431]

64. Supplement resources in GitHub. GitHub. URL: https://github.com/sureshHARDIYA/phd-resources/tree/master/Data/ Review\%20Paper [accessed 2020-11-15]

65. Kelders S, Kok RN, Ossebaard HC, Van Gemert-Pijnen JEWC. Persuasive system design does matter: a systematic review of adherence to web-based interventions. J Med Internet Res 2012 Nov 14;14(6):e152 [FREE Full text] [doi: 10.2196/jmir.2104] [Medline: 23151820]

66. Pugatch J, Grenen E, Surla S, Schwarz M, Cole-Lewis H. Information Architecture of Web-Based Interventions to Improve Health Outcomes: Systematic Review. J Med Internet Res 2018 Mar 21;20(3):e97 [FREE Full text] [doi: 10.2196/jmir.7867] [Medline: 29563076]

67. Kang N, Brinkman WP, Riemsdijk MBV, Neerincx MA. Internet-delivered multi-patient virtual reality exposure therapy system for the treatment of anxiety disorders. In: ECCE '11: Proceedings of the 29th Annual European Conference on 
Cognitive Ergonomics. New York, NY: Association for Computing Machinery; 2011 Aug Presented at: In ECCE - European Conference on Cognitive Ergonomics the Annual Conference of the European Association of Cognitive Ergonomics (pp. 233?236); August, 2011; Rostock Germany p. 233-236 URL: https://doi.org/10.1145/2074712.2074760 [doi: 10.1145/2074712.2074760]

68. Fitzpatrick K, Darcy A, Vierhile M. Delivering Cognitive Behavior Therapy to Young Adults With Symptoms of Depression and Anxiety Using a Fully Automated Conversational Agent (Woebot): A Randomized Controlled Trial. JMIR Ment Health 2017 Jun 06;4(2):e19 [FREE Full text] [doi: 10.2196/mental.7785] [Medline: 28588005]

69. Johnston L, Titov N, Andrews G, Spence J, Dear BF. A RCT of a transdiagnostic internet-delivered treatment for three anxiety disorders: examination of support roles and disorder-specific outcomes. PLoS One 2011;6(11):e28079 [FREE Full text] [doi: 10.1371/journal.pone.0028079] [Medline: 22132216]

70. Holtzblatt K, Beyer H. Contextual design: using customer work models to drive systems design. In: CHI '98: CHI 98 Conference Summary on Human Factors in Computing Systems. New York, NY: Association for Computing Machinery; 1998 Apr Presented at: CHI '98: CHI 98 Conference Summary on Human Factors in Computing Systems; April, 1998; Los Angeles California USA p. 149-150. [doi: 10.1145/286498.286629]

71. Pakkala H, Presser K, Christensen T. Using Google Analytics to measure visitor statistics: The case of food composition websites. International Journal of Information Management 2012 Dec;32(6):504-512 [FREE Full text] [doi:

10.1016/j.ijinfomgt.2012.04.008]

72. Yardley L, Morrison LG, Andreou P, Joseph J, Little P. Understanding reactions to an internet-delivered health-care intervention: accommodating user preferences for information provision. BMC Med Inform Decis Mak 2010 Sep 17;10:52 [FREE Full text] [doi: 10.1186/1472-6947-10-52] [Medline: 20849599]

73. Sundar SS, Marathe SS. Personalization versus Customization: the Importance of Agency, Privacy, and Power Usage. Human Communication Research 2010 Jul 01;36(3):298-322 [FREE Full text] [doi: 10.1111/j.1468-2958.2010.01377.x]

74. Gilbody S, Richards D, Brealey S, Hewitt C. Screening for depression in medical settings with the Patient Health Questionnaire (PHQ): a diagnostic meta-analysis. J Gen Intern Med 2007 Nov 14;22(11):1596-1602 [FREE Full text] [doi: 10.1007/s11606-007-0333-y] [Medline: 17874169]

75. Porterfield D, Rojas-Smith L, Lewis M. A taxonomy of integration interventions between health care and public health. In: RTI Press. Research Triangle Park (NC): RTI Press; Jul 2015.

76. Mukhiya S, Rabbi F, I Pun V, Rutle A, Lamo Y. A GraphQL approach to Healthcare Information Exchange with HL7 FHIR. Procedia Computer Science 2019;160:338-345 [FREE Full text] [doi: 10.1016/j.procs.2019.11.082]

77. Bender D, Sartipi K. HL7 FHIR: An Agile and RESTful approach to healthcare information exchange. 2013 Presented at: Annual IEEE Symposium on Computer-Based Medical Systems; 20-22 June 2013; Porto, Portugal p. 326-331 URL: https:/ /doi.org/10.1109/CBMS.2013.6627810 [doi: 10.1109/cbms.2013.6627810]

78. Suresh KM, Fazle R, Ka IP, Yngve L. An Architectural Design for Self-Reporting E-Health Systems. In: IEEE/ACM International Workshop on Software Engineering for Healthcare (SEH). 2019 Presented at: An architectural design for self-reporting e-health systems. In Proceedings of the 1st International Workshop on Software Engineering for Healthcare (SEH ?19). IEEE Press, 1?8; 2019; Montreal, QC, Canada p. 1-8 URL: https://doi.org/10.1109/SEH.2019.00008 [doi: 10.1109/seh.2019.00008]

79. Ritterband L, Tate DF. The science of internet interventions. Introduction. Ann Behav Med 2009 Aug;38(1):1-3 [FREE Full text] [doi: 10.1007/s12160-009-9132-5] [Medline: 19816750$]$

80. Gamma E, Helm R, Johnson R, Vlissides J. Design Patterns: Abstraction and Reuse of Object-Oriented Design. In: Broy M, Denert E, editors. Pioneers and Their Contributions to Software Engineering. Heidelberg: Springer, Berlin, Heidelberg; 2001.

81. McGaghie W, Bordage G, Shea J. Problem Statement, Conceptual Framework, and Research Question. Academic Medicine 2001;76(9):923-924 [FREE Full text] [doi: 10.1097/00001888-200109000-00021]

\section{Abbreviations}

AR: augmented reality

DSM-5: Diagnostic and Statistical Manual of Mental Disorders, Fifth Edition

FHIR: Fast Healthcare Interoperability Resources

HL7: Health Level Seven International

IA: information architecture

ICT: information communication technology

IDPT: internet-delivered psychological treatment

PRISMA: Preferred Reporting Items for Systematic Reviews and Meta-Analyses

VR: virtual reality 
Edited by $G$ Eysenbach; submitted 04.06.20; peer-reviewed by $R$ Orji, $N$ Forand; comments to author 13.07.20; revised version received 19.08.20; accepted 26.10.20; published 27.11.20

Please cite as:

Mukhiya SK, Wake JD, Inal Y, Pun KI, Lamo Y

Adaptive Elements in Internet-Delivered Psychological Treatment Systems: Systematic Review

$J$ Med Internet Res 2020;22(11):e21066

URL: http://www.jmir.org/2020/11/e21066/

doi: $10.2196 / 21066$

PMID: 33245285

(C) Suresh Kumar Mukhiya, Jo Dugstad Wake, Yavuz Inal, Ka I Pun, Yngve Lamo. Originally published in the Journal of Medical Internet Research (http://www.jmir.org), 27.11.2020. This is an open-access article distributed under the terms of the Creative Commons Attribution License (https://creativecommons.org/licenses/by/4.0/), which permits unrestricted use, distribution, and reproduction in any medium, provided the original work, first published in the Journal of Medical Internet Research, is properly cited. The complete bibliographic information, a link to the original publication on http://www.jmir.org/, as well as this copyright and license information must be included. 